Gogmachadze G.D., Gogmachadze L.G. On some results of agroecological monitoring of soils and land resources of the Russian Federation in 2019

Electronic science-productive magazine

«AgroEcolnfo»

\title{
On some results of agroecological monitoring of soils and land resources of the Russian Federation in 2019
}

Gogmachadze G.D., Gogmachadze L.G.

Lomonosov Moscow State University

\begin{abstract}
The article presents the results of long-term agroecological monitoring of the state of Russian land resources: the dynamics of changes in agrochemical and physico-chemical indicators, the content of organic matter and elements of mineral nutrition of plants in soils; crop productivity; contamination of soils and products with residual amounts of pesticides, oil and petroleum products, heavy metals, nitrates, radionuclides; the problems of erosion and reclamation of agricultural land are highlighted.
\end{abstract}

Ключевые слова: AGROECOLOGICAL MONITORING, HUMUS, MOBILE PHOSPHORUS, EXCHANGE POTASSIUM, ACIDITY, CHEMICAL RECLAMATION, LIMING, PHOSPHORIZATION, GYPSUM, PLANT PROTECTION PRODUCTS, YIELD, FERTILIZERS, PESTICIDE RESIDUES, OIL AND PETROLEUM PRODUCTS, HEAVY METALS, NITRATES, WATER AND WIND EROSION OF SOILS, LAND RECLAMATION

\section{Introduction}

In order to respond in a timely and qualified manner to changes in the environmental situation in a country or in a particular region and take effective measures to correct it, including in the agro-industrial complex, a well-established and effectively functioning agro-ecological monitoring of soils and land resources is necessary.

This article analyzes the results of agroecomonitoring based on the study and generalization of materials from Federal State Statistics Service [1-3], Ministry of Natural Resources of the Russian Federation [4-6], Federal Service for State Registration, Cadastre and Cartography [7], Roshydromet [8], the Ministry of Agriculture of the Russian Federation [9, 10], other organizations [11-16], the results of scientific research in the field of agroecology [17, 18], data from domestic and foreign scientific literature [19-35]. 
Gogmachadze G.D., Gogmachadze L.G. On some results of agroecological monitoring of soils and land resources of the Russian Federation in 2019

Electronic science-productive magazine

«AgroEcolnfo»

\section{Indicators of soil fertility in the Russian Federation}

The soil fertility of farmland is one of the main directions of agroecological monitoring. It determines the ability of soils to ensure the yield of agricultural crops, the ultimate goal of agricultural production, and therefore this direction of agroecomonitoring should be given special attention by the state.

Among the many indicators that characterize soil fertility, the content of humus, the availability of mobile forms of phosphorus and potassium, as well as acidity are of significant importance.

\section{The content of organic matter (humus)}

The main indicator that determines the fertility of the soil is humus. The survey in the Russian Federation as part of its monitoring of 11.3 million hectares in 2019 gave the following results:

- slightly humusized soils - 4.1 million hectares (36.0\%), the most of them;

- soils with a humus content less than the minimum - 2.4 million hectares (21.4\%), i.e. also a significant part of the surveyed;

- medium-humus soils - 3.6 million hectares $(31.9 \%)$;

- highly humus soils -1.2 million hectares $(10.7 \%)$.

These results show that medium-and high-humus soils make up less than half of all the surveyed lands in Russia.

Table 1 shows the results of monitoring the arable land areas of the Russian Federation with distribution over soils with different humus content and federal districts.

Таблица 1. Table 1. The share of soil areas with different humus content in the federal districts of the Russian Federation (according to the results of the survey in 2019), \% of the surveyed area in Russia

\begin{tabular}{|c|c|c|c|c|c|c|}
\hline Federal districts & Low & Weak & Average & Increased & High & Very high \\
\hline Russian Federation & 21,4 & 36,0 & \multicolumn{2}{|c|}{31,9} & \multicolumn{2}{|c|}{10,7} \\
\hline Central & 14,3 & 25,3 & 37,7 & 22,1 & 0,5 & 0,5 \\
\hline North-West & 21,0 & 58,0 & 17,7 & 2,4 & 0,5 & 0,5 \\
\hline South & 24,2 & 52,7 & 18,8 & 4,2 & 0,1 & 0,1 \\
\hline North Caucasian & 4,1 & 79,5 & 10,6 & 5,8 & 0,0 & 0,0 \\
\hline Privolzhsky & 8,6 & 39,6 & 26,3 & 19,3 & 5,1 & 5,1 \\
\hline Uralsky & 1,1 & 13,1 & 51,9 & 30,0 & 3,5 & 3,5 \\
\hline Siberian & 2,0 & 36,6 & 29,4 & 29,4 & 5,7 & 5,7 \\
\hline Far Eastern & 6,2 & 34,8 & 39,7 & 15,4 & 3,0 & 3,0 \\
\hline
\end{tabular}


Gogmachadze G.D., Gogmachadze L.G. On some results of agroecological monitoring of soils and land resources of the Russian Federation in 2019

Electronic science-productive magazine «AgroEcolnfo»

The largest percentage of arable land with low and weak humus content was in the North Caucasus (83.6\%), Northwestern (79.0\%) and Southern (76.9\%) Federal districts, the smallest in the Ural Federal District (14.2\%).

For arable land with an average humus content, the picture is as follows: the largest percentage of such soils is in the Ural Federal District (51.9\%), slightly less in the Far Eastern $(39.7 \%)$ and Central $(37.7 \%)$ Federal districts, the smallest share is in the North Caucasus Federal District (10.6\%).

For arable land with high, high and very high humus content, the situation is generally better in the Ural (33.9\%) and Siberian (32.0\%) federal districts, the worst is in the North Western (3.3\%), Southern (4.3\%) and North-Caucasian (5.8\%) Federal districts.

\section{Soil acidity}

Monitoring of arable land by soil acidity, conducted in 2019 in the Russian Federation on an area of arable land of 11.2 million hectares, showed: acidic soils occupy 4.1 million hectares (36.9\% of the surveyed area), and $2.9 \%$ of them are strongly and very strongly acidic soils; soils with a level of reaction of the soil environment close to neutral occupy an area of 2.2 million hectares $(19.3 \%)$; soils with a neutral reaction - 3.3 million hectares $(29.1 \%)$; soil areas with a $\mathrm{pH}$ above $7.5-1.7$ million hectares (or $14.7 \%$ ).

The following gradation of the degree of soil acidity is used here:

- acidic soils, divided into very strongly acidic ( $\mathrm{pH}<4.0)$, strongly acidic ( $\mathrm{pH} 4.1-4.5)$, medium acidic ( $\mathrm{pH}$ 4.6-5.0), slightly acidic ( $\mathrm{pH}$ 5.1-5.5);

- with the reaction of the soil medium close to neutral ( $\mathrm{pH}$ 5.6-6.0);

- with a neutral reaction of the medium ( $\mathrm{pH}$ 6.1-7.5);

- with a pH above 7.5.

The largest percentage of very strongly acidic $(\mathrm{pH}<4.0)$ and strongly acidic $(\mathrm{pH} 4.1-4.5)$ soils was found in the Far Eastern (7.3\%) and Northwestern (5.9\%) federal districts, the smallestin the Ural and Siberian (1.4\% each).

Medium-acidic ( $\mathrm{pH} 4.6-5.0)$ and slightly acidic ( $\mathrm{pH}$ 5.1-5.5) soils were more pronounced in the Central (53.0\%), Far Eastern (50.4\%) and Ural (48.2\%), to a lesser extent - in the Siberian (29.8\%) federal districts.

Soils with a favorable level of acidity, i.e. the reaction of the soil environment close to 
Gogmachadze G.D., Gogmachadze L.G. On some results of agroecological monitoring of soils and land resources of the Russian Federation in 2019

Electronic science-productive magazine

«AgroEcolnfo»

neutral, occupy a larger percentage of the areas in the Far Eastern (74.6\%), Ural (52.1\%) and Northwestern (42.9\%) federal districts, the smallest percentage-in the Southern $(2.4 \%)$ and North Caucasus $(5.8 \%)$.

The highest percentage of soil areas with a neutral reaction is in the Siberian (30.4\%), Ural (28.7\%), Northwestern (26.9\%) and Central (25.2\%) Federal districts, the least-in the Southern (5.6\%), North Caucasus (7.1\%) and Far Eastern (7.4\%).

\section{Content of mobile phosphorus}

В ходе мониторинга по показателям фосфатного режима почв на территории Российской Федерации в целом было обследовано 11,3 млн га, из которых 2,2 млн га $(19,4 \%)$ - почвы с очень низким и низким содержанием подвижного фосфора, 4,0 млн га $(35,6 \%)$ - со средним, 2,6 млн га (23,4\%) - с повышенным, 1,6 млн га (14,0\%) - с высоким, 0,8 млн га $(7,5 \%)$ - с очень высоким.

During the monitoring of the indicators of the phosphate regime of soils on the territory of the Russian Federation as a whole, 11.3 million hectares were surveyed, of which 2.2 million hectares $(19.4 \%)$ were soils with very low and low mobile phosphorus content, 4.0 million hectares $(35.6 \%)$ - with average, 2.6 million hectares $(23.4 \%)$ - with increased, 1.6 million hectares $(14.0 \%)$ - with high, 0.8 million hectares $(7.5 \%)$ - with very high.

The analysis of the monitoring results for the federal districts showed the presence of large areas with very low and low phosphorus content, which are in dire need of phosphorus fertilizers. Most of these soils in relative terms are in the Far Eastern (59.1\%), Ural (47.9\%) and North Caucasus (39.6\%) Federal districts, slightly less-in the Southern Federal District (26.3\%), and least of all - in the Central (9.5\%), Northwestern (11.1\%) and Volga (15.3\%) Federal districts.

Soils with an average phosphorus content occupy a large percentage of the area in almost all federal districts of Russia: up in the North Caucasian $(48,2 \%)$ and South $(41,3 \%)$ Federal districts, at least - in the far East (18.3\%) and North West $(19,6 \%)$.

As for soils with a high phosphate regime, the highest percentage in the southern $(41,3 \%)$ and Volga (40,6\%), and lowest in the North-West (19,6\%) and far East (20,5\%) Federal districts.

\section{The content of exchangeable potassium}

Monitoring of the potash regime of arable soils of agricultural lands on the territory of the Russian Federation, conducted on an area of arable land of 11.3 million hectares, showed that 
Gogmachadze G.D., Gogmachadze L.G. On some results of agroecological monitoring of soils and land resources of the Russian Federation in 2019

Electronic science-productive magazine

«AgroEcolnfo»

arable land with a very low supply of soils with exchangeable potassium occupies 126.7 thousand hectares $(1.1 \%)$; with a low supply - 908.7 thousand hectares $(8.1 \%)$; with an average $-1,975.3$ thousand hectares (17.6\%); with an increased content of exchangeable potassium (they predominate) -3.1 million hectares $(27.3 \%)$; with a high supply of exchangeable potassium -3.4 million hectares $(30.1 \%)$; with a very high -1.8 million hectares $(15.8 \%)$.

According to the federal districts, the picture is as follows: the most in relative terms of soils with very low and low content of exchangeable potassium are in the North-Western (23.3\%), North-Caucasian (14.3\%) and Central (13.5\%) Federal districts, the least - in the Ural (1.4\%) and Southern (2.7\%) Federal districts. The Volga Federal District is in the middle of the ranking, but it should be taken into account that in absolute terms it is a large area: 249.1 thousand hectares.

For arable land with an average supply of soils with exchangeable potassium in percentage terms, the situation in the federal districts is more even: the largest percentage of such areas was in the North Caucasus (31.3\%), Northwestern (26.1\%), Volga (20.7\%) and Central (19.0\%) federal districts, the smallest-in the Southern and Ural (12.0\%) federal districts.

The situation is even more even in percentage terms - with an increased supply of soils with exchangeable potassium: the maximum is in the Southern $(36.3 \%)$, the minimum is in the North Caucasus $(26.2 \%)$ federal districts.

In terms of arable land with a high supply of exchangeable potassium, which is available in all federal districts, things are somewhat better in the Southern (41.7\%) and Far Eastern (40.2\%), the most lagging in this respect are the Siberian (16.7\%) and Northwestern $(17.6 \%)$ federal districts.

\section{Application of fertilizers and plant protection products}

After a deep recession in the early 2000s, in the middle of this decade, a steady rise in the application of mineral fertilizers in the Russian Federation for crops in agricultural organizations began, which continues at the present time (Fig. 1).

In 2019, 2.7 million tons of mineral fertilizers were applied in Russia as a whole (in terms of $100 \%$ of nutrients), which amounted to $61.0 \mathrm{~kg}$ per 1 ha of sown area (for comparison, in 2010 it was 1.9 million tons and $38.0 \mathrm{~kg}$, respectively). This included: nitrogen fertilizers -1.7 million tons, phosphorus fertilizers (including phosphorous flour) -0.6 million tons, potassium fertilizers 
Gogmachadze G.D., Gogmachadze L.G. On some results of agroecological monitoring of soils and land resources of the Russian Federation in 2019

-0.4 million tons.

The situation is similar with the introduction of organic fertilizers in the Russian Federation for crops in agricultural organizations: there was also a deep decline at the beginning of the century and then a stable rise, which never failed. A particularly sharp rise with the introduction of organic fertilizers occurred in the period 2005-2010. (fig. 2).

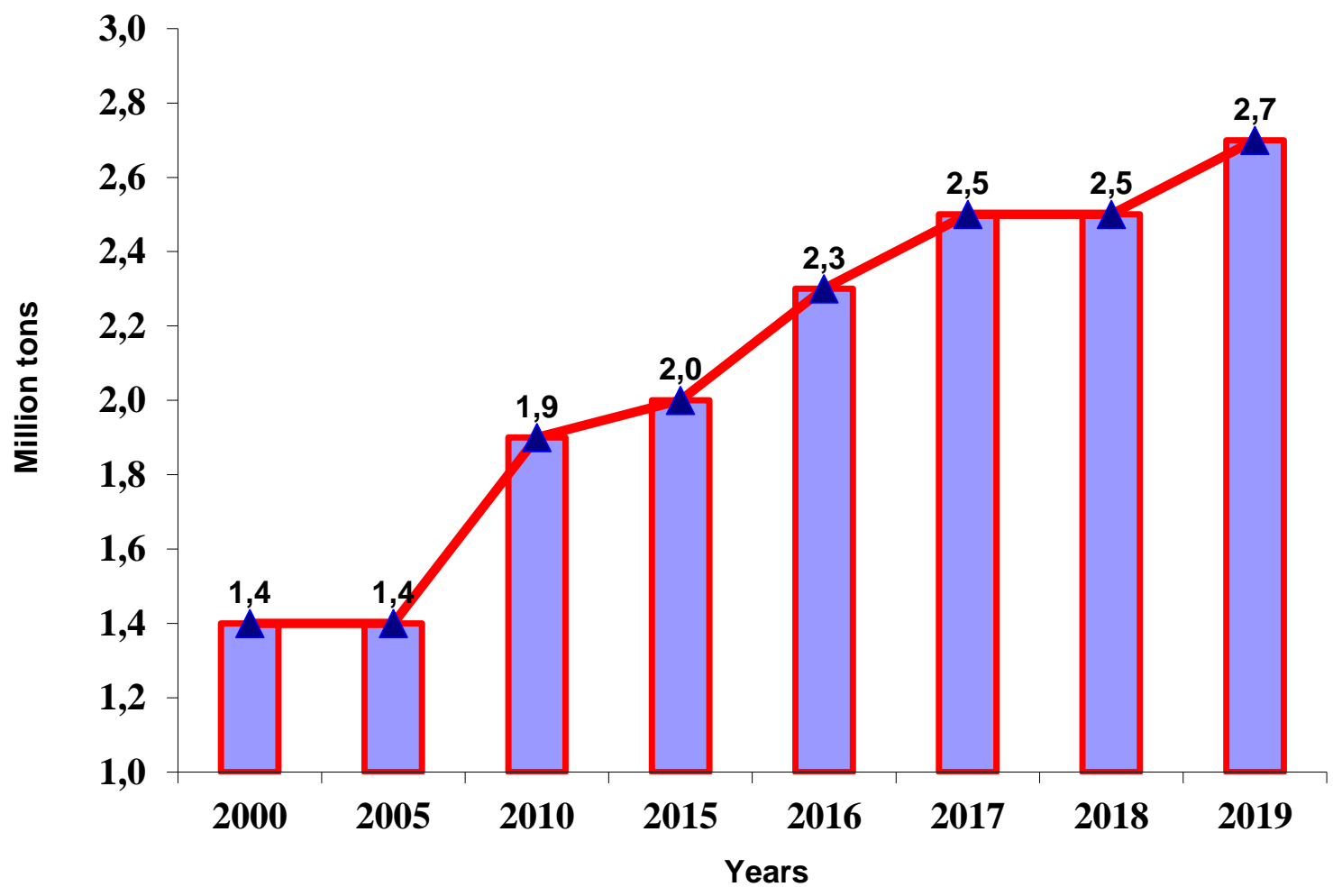

Fig. 1. Dynamics of application of mineral fertilizers for sowing agricultural crops in the Russian Federation (million tons in terms of $100 \%$ nutrients)

In 2019, Russia as a whole introduced 70.7 million tons of organic fertilizers, which, in terms of 1 ha of sown area, amounted to 1.6 tons (for comparison: in 2010, these were, respectively, 53.1 million tons and $1.1 \mathrm{~kg}$ ).

In the course of plant protection works, 101.7 million hectares of land were treated with pesticides in 2019, slightly higher than in previous years: 2015 - 81.8 million hectares; $2016-$ 87.0; 2017-97.2; 2018-94.7 million hectares (Fig. 3).

With a possible increase in the areas treated with pesticides, it is necessary to take into account the need to take measures to protect the soil from contamination with residual amounts of 
Gogmachadze G.D., Gogmachadze L.G. On some results of agroecological monitoring of soils and land resources of the Russian Federation in 2019

Electronic science-productive magazine

«AgroEcolnfo»

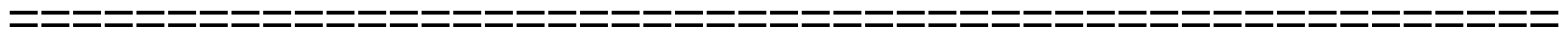

pesticides (OKP), the level of which should not exceed the MPC.

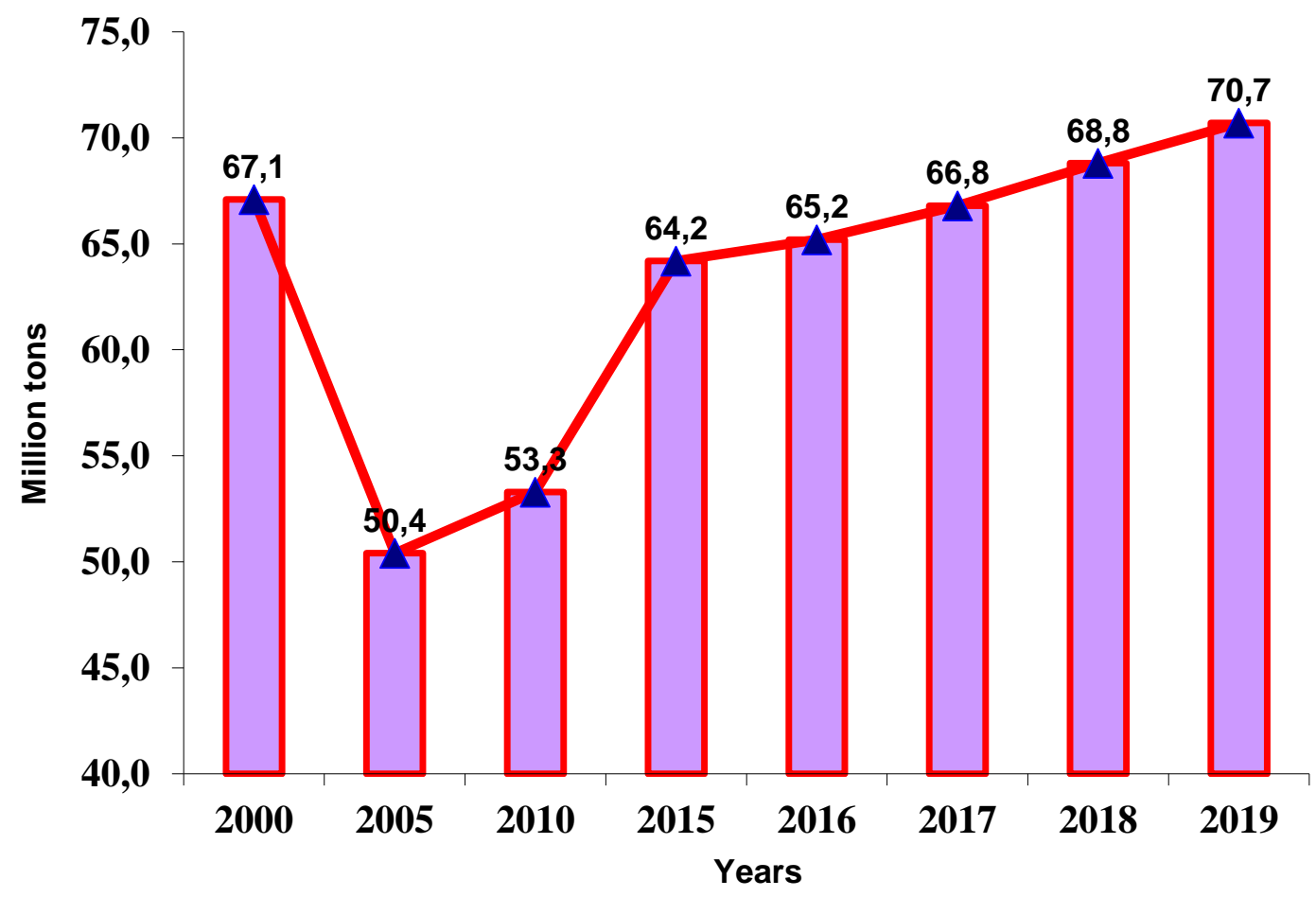

Fig. 2. Dynamics of application of organic fertilizers for sowing agricultural crops in the Russian Federation (million tons)

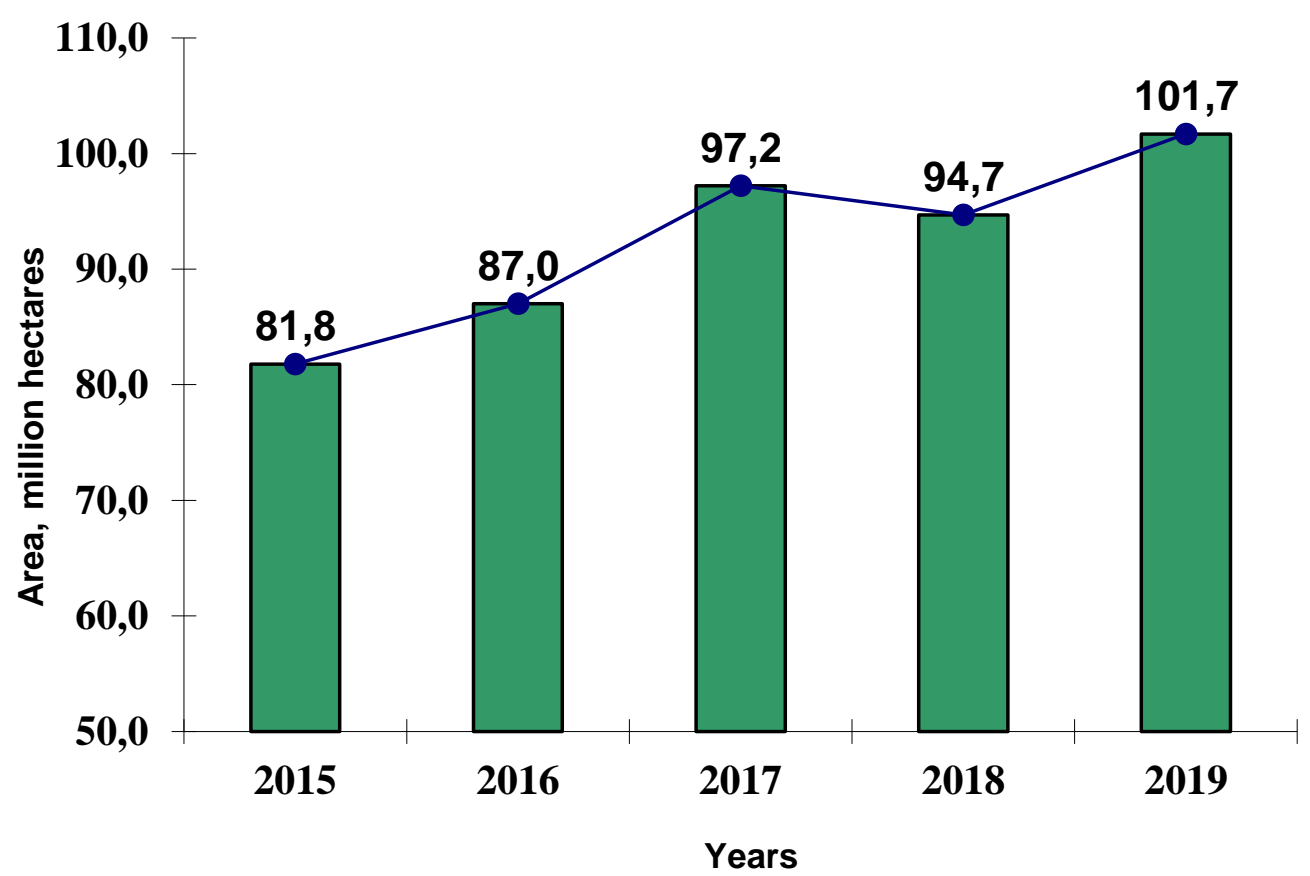


Gogmachadze G.D., Gogmachadze L.G. On some results of agroecological monitoring of soils and land resources of the Russian Federation in 2019

Electronic science-productive magazine «AgroEcolnfo»

\section{Chemical land reclamation}

Fig. 3. Dynamics of the volume of pesticide use in the Russian Federation (million hectares)

The areas of cultivated acidic soils in the Russian Federation have increased slightly in the last 2 years (0.3 million hectares in 2018 and 2019) compared to previous years $(0.2$ million hectares from 2010 to 2017), although they have not yet reached the level of 2000 (0.4 million hectares), as can be seen in Figure 4.

The volume of phosphorization of acidic soils after a sharp drop in 2017 (8.6 thousand hectares, for comparison: in 2016 - 17.5 thousand hectares) has increased significantly in the last 2 years (in 2018 - 12.6 thousand hectares, in 2019 - 21.7 thousand hectares). If this trend continues, it will be possible to approach the areas that are still far away at the beginning of the millennium: 54.2 thousand hectares in 2000 and 43.0 thousand hectares in 2005.

According to the gypsum of saline soils, the situation in 2018 and 2019 worsened compared to 2016 and 2017: in $2018-2.6$ thousand hectares, in 2019-2.4 thousand hectares, while in 2016 there were 3.7 thousand hectares, and in $2017-5.6$ thousand hectares. It is still very far from the level of 2000 (9.2 thousand hectares). 
Gogmachadze G.D., Gogmachadze L.G. On some results of agroecological monitoring of soils and land resources of the Russian Federation in 2019

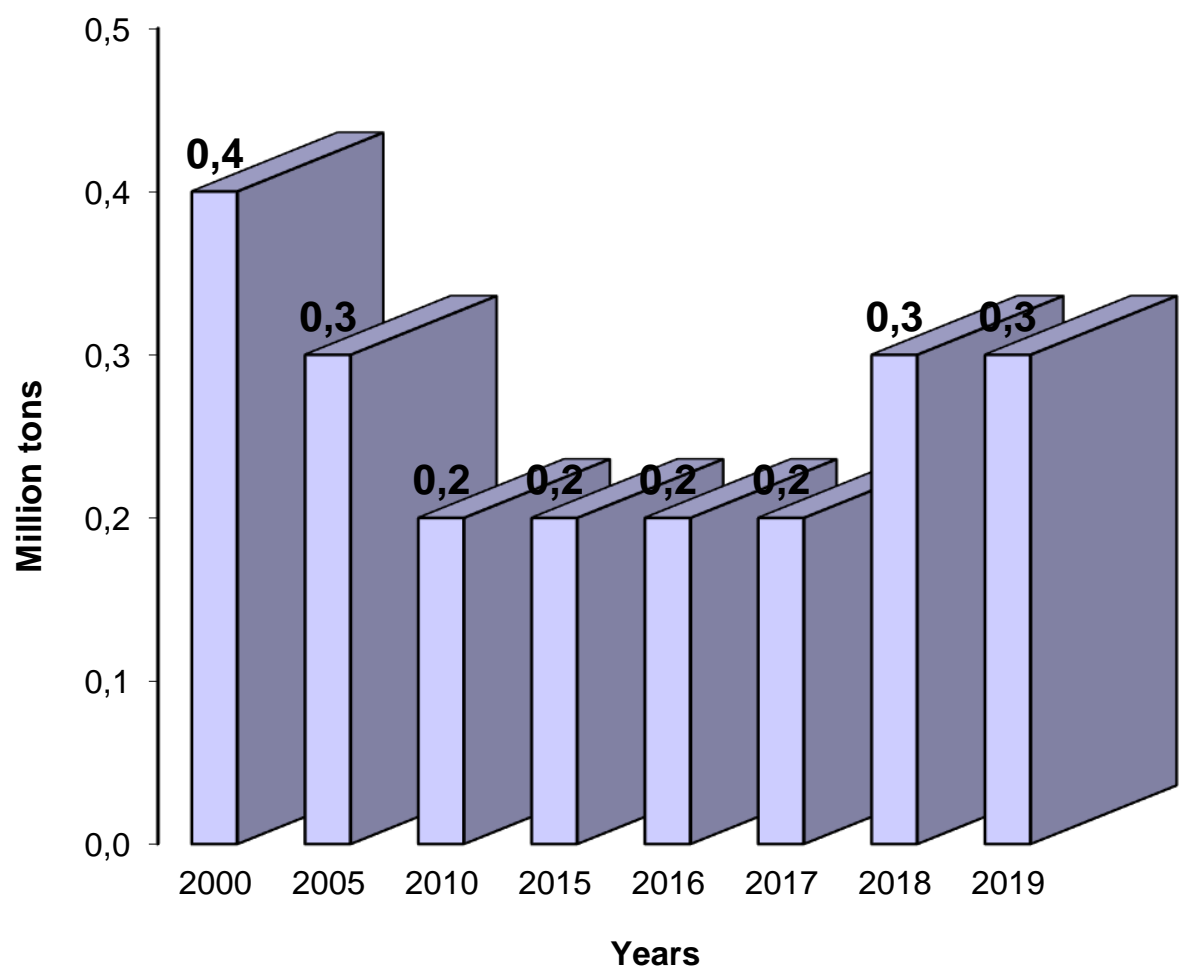

Fig. 4. Dynamics of liming of acidic soils of the Russian Federation (million ha) Contamination of the soils of the Russian Federation with various pollutants

Polluted soil is a danger of toxic substances entering the human body together with food, so monitoring of soil pollution will always be relevant.

In 2019, the organizations of Roshydromet continued the annual survey of soils in the areas of their technogenic pollutants: cities and industrial centers of the Russian Federation.

\section{Soil contamination with residual amounts of pesticides}

A survey conducted by the network divisions of Roshydromet in 2019 on an area of 32.2 thousand hectares showed that the share of soils contaminated with pesticides above the established hygienic standards was 3.3\% in spring and 5.8\% in autumn (for comparison: 2018$1.6 \%$ in spring and $1 \%$ in autumn), i.e. increased compared to 2018 (Fig. 5). The peak of soil contamination with pesticides in both spring and autumn was registered in 2015. 
Gogmachadze G.D., Gogmachadze L.G. On some results of agroecological monitoring of soils and land resources of the Russian Federation in 2019

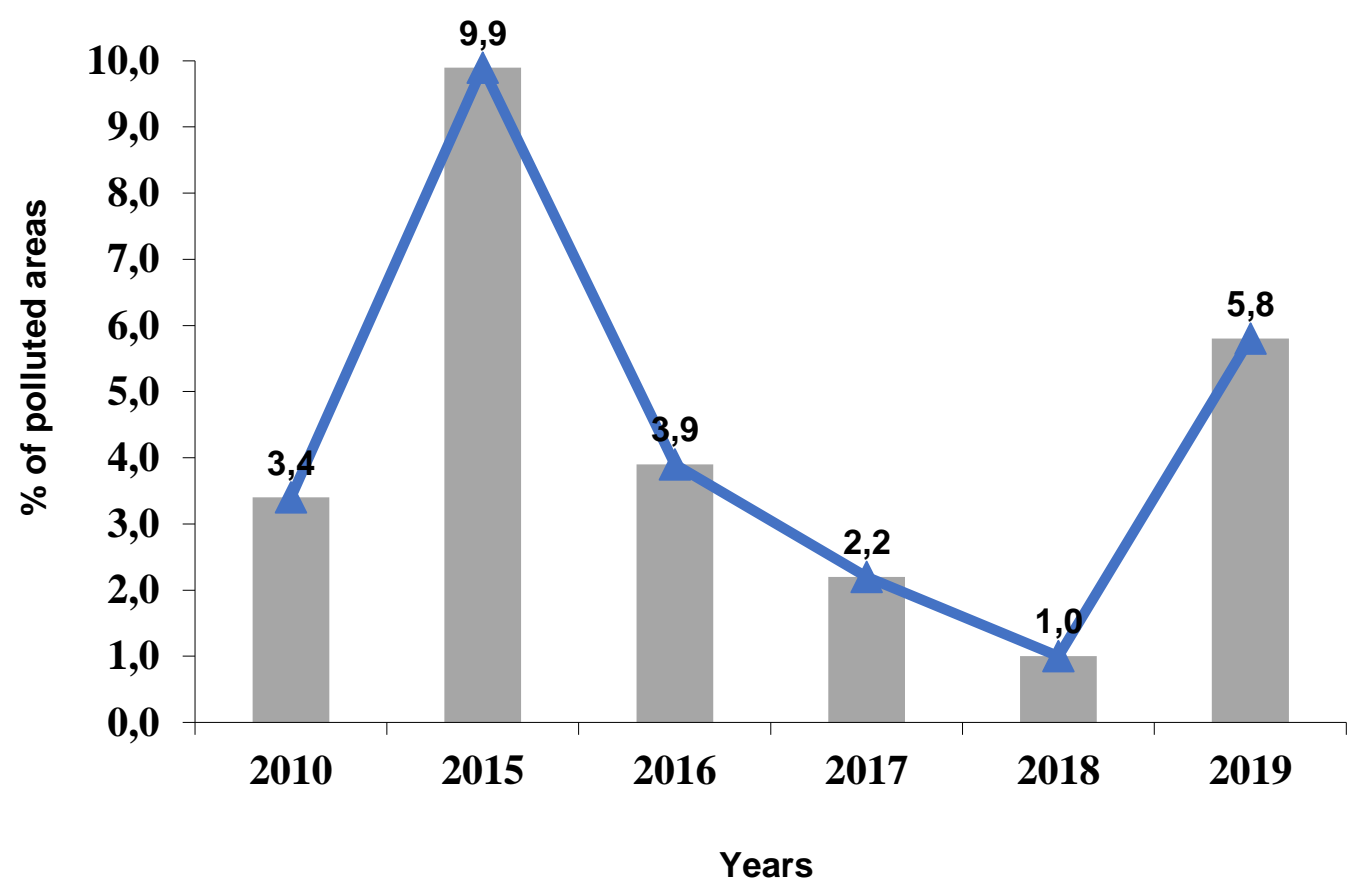

Fig. 5. Dynamics of pesticide contamination of the soils of the surveyed territories in 2010-2019

Sites whose soil was contaminated with pesticides above the established hygiene standards were identified in the surveyed territories of 13 subjects of the Russian Federation (in 2018-8, in 2017-11).

Despite the fact that DDT preparations have not been used on the territory of Russia for a long time, the soil of agricultural enterprises is contaminated with this pesticide to a greater extent than the rest, the content of which in the soil is monitored in the network of Roshydromet. Areas contaminated with dalapon, simazin, THAN and 2,4-D herbicides were also identified.

A survey in 2019 of areas contaminated with residual amounts of pesticides gave the following results: total DDT-29.4 thousand hectares (2.1\%), THAN - 1842 thousand hectares (12.7\%), 2.4-D - 9.8 thousand hectares (4.2\%), Dalapon - 600 thousand hectares $(43.5 \%)$.

\section{Soil contamination with heavy metals}

Observations of soil pollution of TM are carried out mainly in the areas of sources of industrial emissions of TM into the atmosphere. Priority when choosing points of observation for soil pollution of TM are areas where enterprises of non-ferrous and ferrous metallurgy, mechanical 
engineering and metalworking, fuel and energy, chemical and petrochemical industries, enterprises for the production of building materials are located.

In 2019, the mass fractions of aluminum, iron, cadmium, cobalt, magnesium, manganese, copper, nickel, lead, mercury, tin, chromium, zinc and arsenic in various forms were measured in soils: (gross (b), mobile (p), acid-soluble (k, extracted by 5 h nitric acid), water-soluble (water).

The survey of the territories around the sources of TM pollution for 2010-2019 gave the following results: $4.4 \%$ belong to the dangerous category, $9.7 \%$ belong to the moderately dangerous category, $85.9 \%$ of the territories belong to the permissible category.

For the period $2015-2019,3.1 \%$ of settlements belong to the dangerous category of soil pollution, and $9.3 \%$ of settlements belong to the moderately dangerous category, which is slightly better than the indicators of 2010-2014: 5.5\% and 10\%, respectively.

In general, there is a trend towards a decrease in the content of the TM complex in the soils of the surveyed territories, as well as the total number of settlements with dangerous and moderately dangerous categories of soil pollution.

It should be noted that in 2017 and 2019 there was not a single settlement with a dangerous category of soil pollution.

Basically, since 2010, there has been no obvious increase in the total content of TM in the soils of cities and their environs surveyed in 2019.

Thus, according to the monitoring results, there is a tendency to reduce the content of heavy metals in soils.

\section{Land contamination with radionuclides}

Observations of radioactive contamination of environmental components on the territory of Russia are carried out by the radiometric network of Roshydromet.

An analysis of the entire set of observational data showed that the radiation situation on the territory of the Russian Federation has been calm over the past 10 years and has not changed significantly in 2019 compared to 2018. The total activity of radionuclides released into the atmosphere by nuclear industry organizations amounted to $4.85 \mathrm{E}+16 \mathrm{~Bq}$, which is slightly higher (by $0.62 \%$ ) than in 2018 .

In 2019, the nuclear industry organizations did not exceed the established permissible values of radionuclide emissions (as in previous years). In 2019, there were no radiation accidents 
on the territory of Russia and abroad that could affect the radiation situation in the country. The volume of emissions of cobalt-60, strontium-90, zirconium-95, ruthenium-103 and 106, iodine131, caesium-134, caesium-137 in the industry as a whole is less than $1 \%$ of the established standard.

In 2019, 21 cases of high values of $\Sigma \beta$ atmospheric precipitation (more than ten times higher than background levels) were recorded on the territory of Russia (41 cases in 2018).

In general, the precipitation of ${ }^{137} \mathrm{Cs}$, weighted average for the territory of the Russian Federation, in 2019 amounted to $0.13 \mathrm{~Bq} / \mathrm{m}^{2}$ against $0.12 \mathrm{~Bq} / \mathrm{m}^{2}$ in 2018 . In the territories polluted after the Chernobyl accident, the annual precipitation of ${ }^{137} \mathrm{Cs}$ in 2019 practically did not change compared to $2018-0.87$ and $0.85 \mathrm{~Bq} / \mathrm{m}^{2} \cdot$ year, respectively.

The amount of ${ }^{90} \mathrm{Sr}$ precipitation on average in the country was below the detection limit.

The average monthly values of the volume activity of tritium in atmospheric precipitation in 2019 varied in the range of 1.2-2.4 Bq/l. The annual average monthly value of the volume activity of tritium in precipitation throughout the Russian Federation in 2019 increased slightly compared to $2018-1.81 \mathrm{~Bq} / \mathrm{l}$ and $1.65 \mathrm{~Bq} / \mathrm{l}$.

In the areas polluted as a result of the Chernobyl accident, there is a gradual decrease in the levels of radioactive contamination, mainly due to the natural decay of radionuclides.

Thus, in general, the radiation situation in 2019 on the territory of the Russian Federation was stable, the parameters of the radiation situation were at the level of previous years. The situation was also stable within the zones of radioactive contamination due to accidents at the Chernobyl nuclear power plant and the Mayak NPP, as well as in the areas where radiationhazardous facilities are located. The content of technogenic radionuclides in almost all observed environmental objects tends to decrease and does not pose a danger to the population.

\section{Land pollution by oil and petroleum products}

With the constant supply of NP to the soil surface, and even more so with emergency spills of NP, a significant degree of soil contamination occurs.

The entry of NP components into the soil leads to a change in their physical, chemical and microbiological properties. The result of such changes may be a decrease or complete loss of soil fertility. In addition, NP in the process of transformation can form toxic compounds that pose a certain threat to human and animal health. 
Gogmachadze G.D., Gogmachadze L.G. On some results of agroecological monitoring of soils and land resources of the Russian Federation in 2019

Electronic science-productive magazine

«AgroEcolnfo»

There is no standard for the content of NP in soils in Russia. According to the literature data, we can rely on the following approximate indicators: the mass fraction of NP in soils up to $100 \mathrm{mg} / \mathrm{kg}$ is background, they do not pose an environmental hazard to the environment. Mass fractions from 100 to $500 \mathrm{mg} / \mathrm{kg}$ can be considered an increased background. Contaminated soils can be considered soils containing more than $500 \mathrm{mg} / \mathrm{kg}$ of NP. At the same time, mass fractions from 500 to $1000 \mathrm{mg} / \mathrm{kg}$ in soils correspond to moderate soil pollution, from 1000 to 2000 moderately dangerous pollution, from 2000 to $5000 \mathrm{mg} / \mathrm{kg}$ - severe, dangerous pollution and over $5000 \mathrm{mg} / \mathrm{kg}$ - very severe pollution.

Pollution of land, including agricultural land, with oil and petroleum products is observed mainly in the territories of oil-producing regions: the West Siberian, North Caucasus, the Komi Republics, Bashkortostan, Tatarstan, as well as the regions of the Middle and Lower Volga region. For example,in the West Siberian region, more than half of the exploited oil fields have a crisis environmental situation.

More than 200 thousand $\mathrm{km}$ of main pipelines and more than 350 thousand $\mathrm{km}$ of field pipelines are currently being operated on the territory of the Russian Federation. Physical and moral deterioration of technical equipment and the lack of proper control over the state of technological systems lead to an increase in the number of accidents and hydrocarbon pollution of significant territories.

Every year, up to 35 thousand accidents occur at the fields, losses account for at least $3.5 \%$ of all oil produced. In the tundra zone of Russia, as a result of the development of oil and gas fields, the development of the energy complex and transport infrastructure, the degradation of vegetation cover has reached 70 million hectares in recent years.

In 2019, observations of soil contamination of NP in the area of the accident that occurred in March 1993 on 654 km of the Krasnoyarsk-Irkutsk oil pipeline were continued. Compared with the results of the previous survey conducted in 2016, there is a significant decrease in the content of petroleum products in the soils of the oil slick zone (by 5 times) and the zone outside the initial oil spill (by 3 times).

The survey results show a tendency to decrease the content of NP in the area of an emergency oil spill (oil spot zone) for the entire observation period from the moment of the accident. 
Gogmachadze G.D., Gogmachadze L.G. On some results of agroecological monitoring of soils and land resources of the Russian Federation in 2019

Electronic science-productive magazine

«AgroEcolnfo»

\section{Contamination of crop production with nitrates}

The accumulation of nitrates in plants is associated with the use of nitrogen, which enters the soil, and then - into plants, with nitrogen and organic fertilizers applied.

Nitrates are a mandatory part of the nitrogen cycle in nature, a source of nitrogen nutrition of plants. They are not dangerous to humans up to a certain level, when an excessive amount of them is formed. After entering the human body, it turns into nitrites, which pose a great and real danger to human health. Therefore, monitoring of soils and products for excess nitrate content is carried out annually.

The results of observations over the past five years show a tendency to decrease or maintain the content of nitrates in soils at the same level, which is confirmed by the results of a survey in 2019 of territories in Western Siberia, Samara, Orenburg and Sverdlovsk regions.

Soil contamination with nitrates in 2019 was detected on a one-time basis at the level of 1 MPC in the Kirovsky district of Novosibirsk.

\section{Soil erosion in the Russian Federation}

Soil erosion is the most extensive and harmful of all types of soil degradation. This is due to its wide distribution, with the depth and irreversibility of changes in the soil cover. The ecological danger of modern erosion lies in the fact that the ecological balance is disturbed on most lands, as a result of which the natural fertility of the soils decreases, their degradation occurs. The latter has a negative impact on the water, air and food regime of soils and, as a result, on the growth and development of cultivated plants.

Currently, the development and spread of erosion processes in the Russian Federation remains one of the main sources of loss of soil fertility and crop resources, environmental degradation. Soil erosion - the process of their depletion-is one of the most common types of soil degradation, causing great economic and environmental damage.

\section{Wind erosion (deflation)}

Wind erosion (deflation) is characterized by the removal of the smallest soil particles and manifests itself on all types of terrain, covering huge territories. It is most often manifested in the spring, when the soil is loosened, dried, sprayed and not covered with vegetation and crop residues. The spread of wind erosion (deflation) on the soil surface leads to an imperceptible but constant 
decrease in soil fertility, causes great damage to agriculture, as a result, a fifth of crop production does not reach.

In 2019, soil monitoring on the territory of the Russian Federation, including the identification of the process of wind erosion (deflation), was carried out on an area of arable land of 12773.37 thousand hectares. Soils subject to wind erosion (deflation) were identified on an area of 1643.76 thousand hectares, which is $12.9 \%$ of the total surveyed area of agricultural land.

The most significant areas of eroded land in 2019 were identified in the Volga Federal District -566.24 thousand hectares, which is $34.4 \%$ of the total area subject to wind erosion (deflation) in the Russian Federation, as well as in the Siberian (27.5\%) and Southern (22.8\%) federal districts. Lower values for the spread of wind erosion were found in the North Caucasus $(10.8 \%)$, Central (3.4\%), Far Eastern (1.0\%) and Ural (0.2\%) federal districts. There are no lands exposed to wind erosion (deflation) in the North-Western Federal District.

The largest percentage of agricultural land subject to wind erosion is in the North Caucasus (24.3\% compared to the area surveyed in the district), Siberian $(22.8 \%)$, Volga $(18.7 \%)$ and Southern (15.7\%) federal districts. Lower values were observed in the Far Eastern (3.6\%), Central $(2.0 \%)$ and Ural $(0.3 \%)$ federal districts. In the North-Western Federal District, no lands subject to wind erosion (deflation) of agricultural land have been identified.

According to the degree of manifestation of wind erosion (deflation), the soils in accordance with the loss of the humus horizon are divided into:

- weakly ventilated - reduction of the humus layer to $20 \%$;

- medium-sized-reduction of the humus layer by $21-40 \%$;

- highly inflated - reduction of the humus layer by 41-60\%.

According to the results of the survey in 2019, the main share of eroded soils is poorly ventilated soils, occupying 1,309.70 thousand hectares - about $79.7 \%$ of the total area of the surveyed agricultural land on the territory of the Russian Federation, subject to wind erosion (deflation). Medium-leached soils are distributed on 233.15 thousand hectares (14.2\%), highly leached-on 100.91 thousand hectares $(6.1 \%)$.

Considering the situation in the federal districts gives the following picture: the soils of agricultural lands with a strong degree of deflation are distributed mainly in the Southern Federal District (22.2\% of the area exposed to wind erosion in the federal district), which is the highest 
Gogmachadze G.D., Gogmachadze L.G. On some results of agroecological monitoring of soils and land resources of the Russian Federation in 2019

Electronic science-productive magazine

«AgroEcolnfo»

indicator among the federal districts, more than 3 times higher than the average value for the Russian Federation. Insignificant territories of highly inflated soils were identified in the North Caucasus (3.9\% of the area exposed to wind erosion in the federal district), Siberian $(2.1 \%)$ and Central $(1.5 \%)$ Federal districts. On the territory of the North-Western, Ural and Far Eastern Federal Districts, no soils subject to a strong degree of wind erosion (deflation) were detected.

Agricultural lands with an average degree of deflation are distributed in the Central Federal District (30.8\% of the area exposed to deflation identified in the Federal District), as well as in the Southern (27.7\%), Far Eastern (20.7\%) and Siberian (16.7\%) Federal districts. On the territory of the North Caucasus Federal District, agricultural lands exposed to wind erosion with an average degree of manifestation were also found in a significant part of the area with detected wind erosion $(14.8 \%)$. In the Volga Federal District, such farmland was found in an insignificant part of the territory $(1.3 \%)$. In the North-Western and Ural Federal districts, medium-deflated soils were not detected.

The areas of agricultural land with a weak degree of deflation were identified in almost all federal districts and occupy significant territories. The largest ones in relative terms were found in the Ural Federal District (100.0\% of the area with detected wind erosion in the district), the Volga (98.7\%), the North Caucasus (81.2\%), the Siberian (81.1\%) and the Far Eastern (79.3\%) federal districts. In the Central (67.8\%) and Southern (50.1\%) Federal districts, agricultural lands exposed to wind deflation with a weak degree of manifestation were also found in a significant part of the territory. No such farmlands have been identified in the North-Western Federal District.

Table 2 shows the situation with the development of wind erosion (deflation) in the Russian Federation as of 1.01.2020 in the context of federal districts.

Таблица 2. Распределение площадей, подверженных ветровой эрозии, по федеральным округам

\begin{tabular}{|c|c|c|c|c|c|c|}
\hline \multirow{2}{*}{ Federal districts } & \multirow{2}{*}{$\begin{array}{l}\text { Surveyed } \\
\text { area, } \\
\text { thousand } \\
\text { hectares }\end{array}$} & \multicolumn{2}{|c|}{$\begin{array}{c}\text { Subject to } \\
\text { wind erosion }\end{array}$} & \multicolumn{3}{|c|}{ including $\%$ of the eroded } \\
\hline & & $\begin{array}{l}\text { thousand } \\
\text { hectares }\end{array}$ & $\begin{array}{l}\% \text { of the } \\
\text { surveyed }\end{array}$ & weak & average & strong \\
\hline Russian Federation & 12773,37 & 1643,76 & 12,9 & 79,7 & 14,2 & 6,1 \\
\hline Central & 2802,18 & 55,12 & 2,0 & 67,8 & 30,8 & 1,5 \\
\hline North-West & 516,67 & - & - & - & - & - \\
\hline South & 2387,69 & 375,13 & 15,7 & 50,1 & 27,2 & 22,2 \\
\hline North Caucasian & 727,87 & 176,86 & 24,3 & 81,2 & 14,8 & 3,9 \\
\hline Privolzhsky & 3021,26 & 566,24 & 18,7 & 98,7 & 1,3 & - \\
\hline
\end{tabular}


Gogmachadze G.D., Gogmachadze L.G. On some results of agroecological monitoring of soils and land resources of the Russian Federation in 2019

Electronic science-productive magazine

"AgroEcolnfo»

\begin{tabular}{|c|c|c|c|c|c|c|}
\hline Uralsky & 884,90 & 2,49 & 0,3 & 100,0 & - & - \\
\hline Siberian & 1984,92 & 451,73 & 22,8 & 81,1 & 16,7 & 2,1 \\
\hline Far Eastern & 447,88 & 16,19 & 3,6 & 79,3 & 20,7 & - \\
\hline
\end{tabular}

\section{Water erosion}

Water erosion is the most extensive and destructive type of soil degradation. It is characterized by the destruction and depletion of the soil cover under the influence of melt, rain or irrigation water.

Water erosion remains one of the main sources of loss of soil fertility resources, reduction of its productivity and, ultimately, the efficiency of agricultural production.

On the territory of the Russian Federation in 2019, soil monitoring, including the identification of the process of water erosion, was carried out on the lands of agricultural lands located on the territory of 276 municipalities (districts) in 75 subjects of the Russian Federation.

The total surveyed area of farmland in the Russian Federation in 2019 amounted to 12,773. 37 thousand hectares. The spread of water erosion was detected on an area of 2,467. 92 thousand hectares (19.3\% of the total surveyed area of farmland). The processes of water erosion development take place in all regions of the Russian Federation. Especially significant areas are in the Volga Region (45.9\% of the total area of agricultural land exposed to water erosion in the Russian Federation in 2019), the Southern (21.9\%) and Siberian (16.1\%) federal districts. The areas located in the North Caucasus (7.5\%), Central (7.2\%), Northwestern (0.6\%), Far Eastern $(0.5 \%)$ and Ural $(0.3 \%)$ Federal districts are less susceptible to water erosion.

The largest areas of agricultural land with detected water erosion in relative terms were noted in the Volga (37.5\% of the territory surveyed in the Federal district), North Caucasus (25.6\%), Southern (22.7\%) and Siberian (20.0\%) federal districts. The soils located in the Central (6.3\%), Far Eastern (2.9\%) and Northwestern (2.8\%) Federal districts are less susceptible to water erosion. Insignificant areas of eroded soils were found in the Ural (0.7\%) Federal District.

Water erosion based on the assessment of the intensity of the annual washout of the humus horizon is divided into the following categories:

- slightly washed-the intensity of the annual washout of the fertile soil layer is $0.5-1.0 \mathrm{t} /$ ha;

- average washed-1.0-5.0 t/ ha;

- highly washed-5.0-10.0 t / ha. 
Gogmachadze G.D., Gogmachadze L.G. On some results of agroecological monitoring of soils and land resources of the Russian Federation in 2019

Electronic science-productive magazine

«AgroEcolnfo»

The total area of agricultural land exposed to water erosion identified in 2019 is distributed according to the degree of erosion as follows. Weakly washed soils are the most widespread, occupying an area of 2,046. 20 thousand hectares, which is $82.9 \%$ of the area of agricultural land exposed to water erosion in the Russian Federation identified in 2019. Medium-washed soils cover an area of 352.94 thousand hectares (14.3\%), strongly washed - 68.78 thousand hectares $(2.8 \%)$.

According to the results of the survey conducted in 2019, no soils subject to a strong degree of water erosion were found on the territory of the North-Western and Ural Federal districts. Heavily washed soils are mainly distributed only in the Southern (5.0\%) and North Caucasus (4.5\%) federal districts. Insignificant territories of soils with a strong degree of washout were identified in the Volga (2.4\% of the identified area of agricultural land subject to water erosion), Siberian (1.2\%) and Central (1.0\%) Federal districts. To a lesser extent, the territories of soils with a strong degree of washout were noted in the Far Eastern Federal District $-0.04 \%$ of the area exposed to water erosion identified in the federal district.

The largest areas of water erosion with an average degree of manifestation are located in the Southern (28.2\%), North Caucasus (17.5\%) and Central (16.7\%) Federal districts. Smaller areas with an average degree of water erosion were found in the Northwestern (12.9\%), Siberian $(10.4 \%)$ and Volga (8.3\%) federal districts. Insignificant shares of agricultural land with an average degree of water erosion are located in the Far Eastern Federal District (4.9\%). On the territory of the Ural Federal District, no medium-washed soils were found on agricultural land.

Weakly washed soils on agricultural lands were noted on the territory of all federal districts of Russia, including the most significant proportions of such soils were found in the Ural (100.0\% of the area of land in the district exposed to water erosion in 2019), the Far Eastern (95.0\%), Volga $(89.4 \%)$, Siberian (88.4\%), Northwestern (87.1\%), Central (82.2\%), North Caucasus $(78.0 \%)$ and Southern $(66.7 \%)$ federal districts.

Table 3 shows the situation with the development of water erosion in the Russian Federation as of 1.01.2020 in the context of federal districts.

Table 3. Distribution of areas subject to water erosion by Federal districts

\begin{tabular}{|c|c|c|c|c|c|c|}
\hline \multirow{2}{*}{ Federal districts } & \multirow{2}{*}{$\begin{array}{l}\text { Surveyed } \\
\text { area, } \\
\text { thousand } \\
\text { hectares }\end{array}$} & \multicolumn{2}{|c|}{$\begin{array}{c}\text { Subject to } \\
\text { water erosion }\end{array}$} & \multicolumn{3}{|c|}{ including $\%$ of the eroded } \\
\hline & & $\begin{array}{l}\text { thousand } \\
\text { hectares }\end{array}$ & $\begin{array}{l}\text { \% of the } \\
\text { surveyed }\end{array}$ & $\begin{array}{l}\text { Weakly- } \\
\text { washed }\end{array}$ & $\begin{array}{c}\text { medium- } \\
\text { washed }\end{array}$ & \\
\hline
\end{tabular}


Gogmachadze G.D., Gogmachadze L.G. On some results of agroecological monitoring of soils and land resources of the Russian Federation in 2019

Electronic science-productive magazine

«AgroEcolnfo»

\begin{tabular}{|c|c|c|c|c|c|c|}
\hline & & & & away & & away \\
\hline Russian Federation & 12773,37 & 2467,92 & 19,3 & 82,9 & 14,3 & 2,8 \\
\hline Central & 2802,18 & 177,01 & 6,3 & 82,2 & 16,7 & 1,0 \\
\hline North-West & 516,67 & 14,33 & 2,8 & 87,1 & 12,9 & - \\
\hline South & 2387,69 & 542,20 & 22,7 & 66,7 & 28.2 & 5,0 \\
\hline North Caucasian & 727,87 & 186,54 & 25,6 & 78,0 & 17,5 & 4,5 \\
\hline Privolzhsky & 3021,26 & 1132,20 & 37,5 & 89,4 & 8,3 & 2,4 \\
\hline Uralsky & 884,90 & 6,33 & 0,7 & 100,0 & - & - \\
\hline Siberian & 1984,92 & 396,36 & 20,0 & 88,4 & 10,4 & 1,2 \\
\hline Far Eastern & 447,88 & 12,95 & 2,9 & 95,0 & 4,9 & 0,04 \\
\hline
\end{tabular}

\section{Condition and use of reclaimed land}

In the Russian Federation in 2019, there were 9.45 million hectares of reclaimed land, including 4.67 million hectares of irrigated and 4.78 million hectares of drained. In agricultural production, 7.07 million hectares of reclaimed land (75\% of the available land) were used for growing crops, including 3.82 million hectares of irrigated and 3.25 million hectares of drained land (Table 4).

In 2010-2019, the reclamation condition of irrigated and drained lands as a whole remained at the same level; the area of land in an unsatisfactory reclamation condition practically did not change. At the same time, from 2010 to 2019, the total area of irrigated land increased by 349.8 thousand hectares, and the total area of drained land decreased by 73.9 thousand hectares. According to the results of observations, in 2019, the total area where land improvement and the technical level of reclamation systems are required was 6073.1 thousand hectares (in 2018 5984.4 thousand hectares, in 2017 - 6020.0 thousand hectares, in 2016 - 5966.5 thousand hectares). ha), of which 2658.4 thousand hectares are on irrigated lands and 3414.7 thousand hectares are on drained ones. 
Gogmachadze G.D., Gogmachadze L.G. On some results of agroecological monitoring of soils and land resources of the Russian Federation in 2019

Electronic science-productive magazine

«AgroEcolnfo"

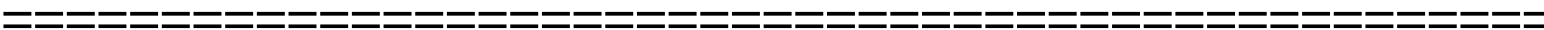

Table 4. Reclamation status of irrigated and drained lands (as of 1.01.2020), thousand hectares

\begin{tabular}{|c|c|c|c|c|c|c|c|c|}
\hline \multirow{2}{*}{ Federal districts } & \multicolumn{4}{|c|}{ Irrigated land } & \multicolumn{4}{c|}{ Drained lands } \\
\cline { 2 - 10 } & in total & good & satisfactory & unsatisfactory & in total & good & satisfactory & unsatisfactory \\
\hline Russian Federation & 4664,595 & 2433,601 & 1324,338 & 906,656 & 4781,437 & 924,338 & 2204,450 & 1652,649 \\
\hline Central & 234,105 & 216,568 & 142,854 & 124,814 & 1355,421 & 238,180 & 568,801 & 587,591 \\
\hline North-West & 16,469 & 4,894 & 6,469 & 5,106 & 1821,331 & 225,409 & 1009,599 & 586,323 \\
\hline South & 1513,766 & 823,897 & 415,599 & 274,270 & 54,574 & 26,053 & 19,891 & 8,630 \\
\hline North Caucasian & 983,936 & 409,295 & 226,042 & 348,599 & 19,534 & 7,447 & 7,339 & 4,748 \\
\hline Privolzhsky & 146,877 & 636,695 & 235,485 & 35,631 & 368,488 & 110,892 & 207,392 & 98,932 \\
\hline Uralsky & 33,922 & 59,717 & 47,715 & 12,625 & 49,961 & 3,778 & 90,783 & 56,478 \\
\hline Siberian & 333,099 & 209,998 & 105,875 & 17,226 & 172,076 & 39,530 & 70,857 & 61,689 \\
\hline Far Eastern & 305,221 & 72,537 & 144,299 & 88,385 & 751,095 & 273,049 & 229,788 & 248,258 \\
\hline
\end{tabular}


Gogmachadze G.D., Gogmachadze L.G. On some results of agroecological monitoring of soils and land resources of the Russian Federation in 2019

Electronic science-productive magazine

«AgroEcolnfo»

Almost half of the existing irrigation systems (2.405 million hectares) need a set of measures to improve their technical level, of which systems on an area of 2.14 million hectares require reconstruction work.

Drainage systems on an area of 1.41 million hectares (29.5\% of the availability) need to be carried out for restoration and reconstruction. The unsatisfactory condition of some of the existing reclaimed lands creates an unfavorable ecological situation on these lands, as well as on the territories adjacent to them, causing flooding of agricultural land and limiting their use in agricultural turnover.

\section{Crop productivity}

The integral indicator of the effectiveness of the work carried out in agriculture is the yield of agricultural crops. A large number of factors have a significant impact on the yield level, including the composite indicators of soil fertility discussed above, the introduction of mineral and organic fertilizers, plant protection products, in particular, pesticides.

As you know, after 2005, with a yield of $18.5 \mathrm{c} / \mathrm{ha}$, the rise began until 2008, when a yield of $23.8 \mathrm{c} /$ ha was achieved. Then, after a slight decline in 2009 (22.7 c/ha), in the 2010 dry year, the yield (18.3 c/ha) fell to the level of 2005. But then began a remarkable recovery, and in the Russian Federation, the yield of grain and leguminous crops from 2015 to 2019 were held at a very similar level (Fig. 6).

In particular, in 2019 was achieved yield of $26.7 \mathrm{~kg} / \mathrm{ha}$, which, according to preliminary data, was exceeded in 2020: 28,6 kg/ha (Fig. 6).

The potato yield in the Russian Federation from 2015 to the present is kept at approximately the same level, significantly exceeding the level of the first decade of the 21 st century $(164,0 ; 158,0 ; 163,0 ; 170,0 ; 178,1$ c/ha, respectively, in 2015-2019). In 2020, according to preliminary data, there was a slight decrease in yield compared to the previous year, 2019: 166.0 c/ha.

The yield of vegetable crops in the country has been growing almost steadily since 2000 (143.0 c/ha): in 2015 - $226 \mathrm{c} / \mathrm{ha}$, in 2016 - 229, in 2017-241, in 2018-243, in 2019-251 c / ha. although in 2020, according to preliminary data, there was a slight decrease in yield $(245 \mathrm{c} / \mathrm{ha})$ compared to the previous year, 2019, the trend of increasing the yield of vegetable crops in the following years is likely to continue. 
Gogmachadze G.D., Gogmachadze L.G. On some results of agroecological monitoring of soils and land resources of the Russian Federation in 2019
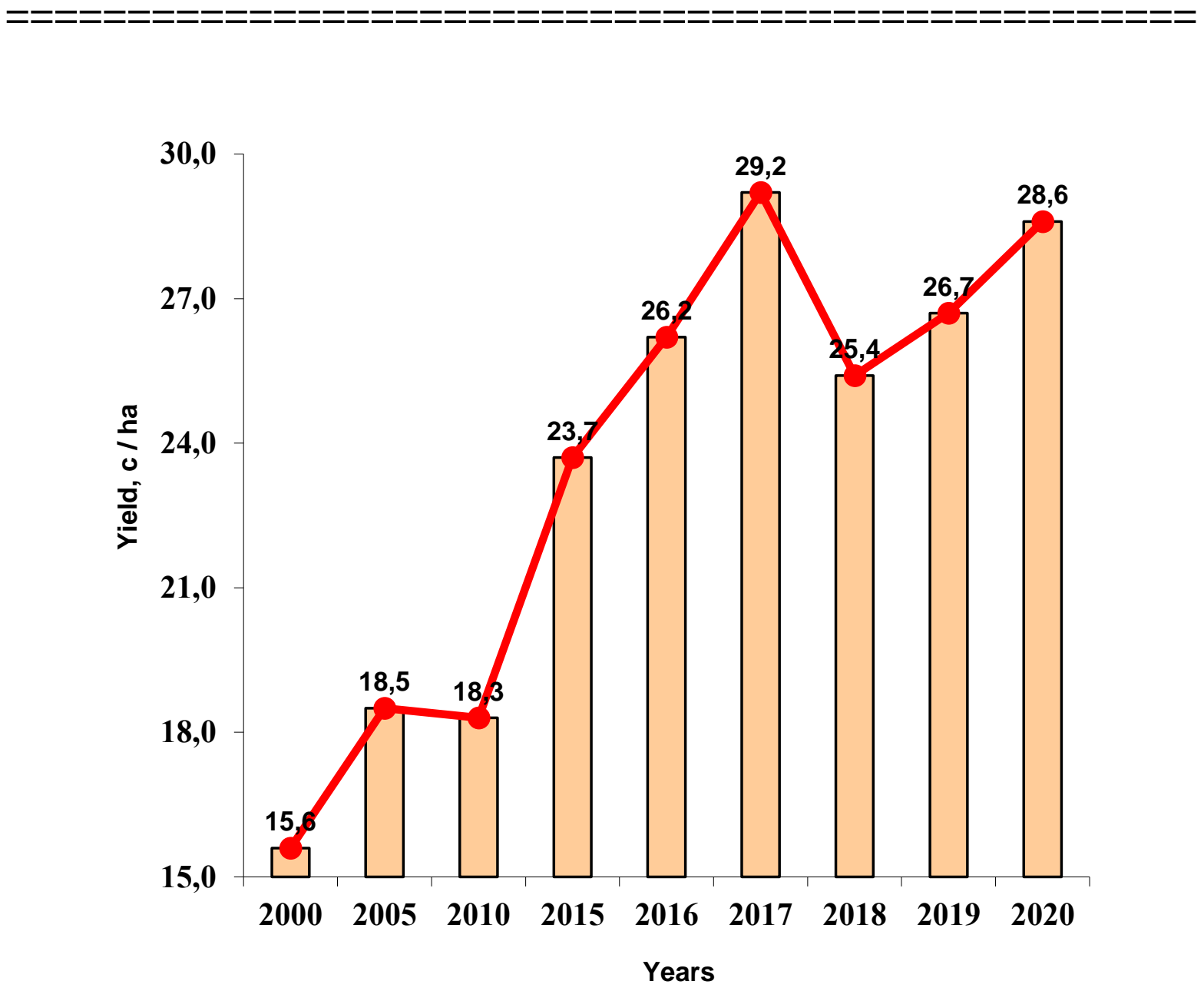

Fig. 6. Dynamics of grain and leguminous crops yield in the Russian Federation

Thus, the analysis of data on crop yields in the Russian Federation indicates that it is generally not very fast, but still growing and approaching the level of the most productive 2017.

\section{Conclusion}

An analysis of the state of the environment and, first of all, the soil in the Russian Federation and the regions in 2019 shows that there has been no real improvement in this area of life for a long time. The situation with environmental protection in agriculture remains very alarming, as the contamination of soils and agricultural products with pesticides, industrial, toxic and household waste continues. We have to state an increase in waste generation, emissions from metallurgical, oil refining and other industries, pollution of urban and rural territories with household waste, and the negative impact on the environment of an increasing number of cars.

This leads to the conclusion that it is necessary to adjust approaches to farming taking into 
Gogmachadze G.D., Gogmachadze L.G. On some results of agroecological monitoring of soils and land resources of the Russian Federation in 2019

Electronic science-productive magazine

"AgroEcolnfo»

account environmental criteria and environmental protection.

It is necessary to increase the level of environmental expertise of modern farming systems, projects of economic initiatives and agricultural development programs on environmental sustainability and commodity and economic productivity of agricultural landscapes, livestock complexes, their placement on the territory, etc.

However, the country still faces the threat of reducing scientific research due to a decrease in state support for science. Many scientific institutions and breeding centers are forced to suspend their research on cytology, genetics, biotechnology, biochemistry, molecular biology, plant physiology, phytopathology. This creates a threat, first of all, to fundamental research, on which applied scientific developments are based. The main reason is the insufficient funding of scientific research in the field of environmental ecology in the Russian Federation, as well as specific practical measures aimed at improving the environmental situation in the country.

Only a comprehensive solution to the problems of domestic agriculture can put it a level that meets the modern world development.

\section{List of sources used}

1. Environmental protection in the Russian Federation in 2011, 2013, 2015, 2017, 2019. Statistical collection. - M.: Federal State Statistics Service.

2. Russian statistical Yearbook 2009, 2010, 2011, 2012, 2013, 2014, 2015, 2016, 2017, 2018, 2019. - M.: Federal State Statistics Service.

3. Agriculture in Russia, 2009, 2011, 2013, 2019. - M.: Federal state statistics service.

4. State reports "On the State and environmental protection of the Russian Federation in the 2010, 2011, 2012, 2013, 2014, 2015, 2016, 2017, 2018, 2019 years." - M.: Ministry of Natural Resources of the Russian Federation.

5. The radiation situation on the territory of Russia and the neighbouring States 2003, 2004, 2005, 2006, 2007, 2008, 2009, 2010, 2011, 2012, 2013, 2014, 2015, 2016, 2017, 2018, 2019. Yearbook. - Obninsk: Ministry of Natural Resources of the Russian Federation.

6 . The state of pesticide pollution of the natural environment of the Russian Federation in 2010, 2011, 2012, 2013, 2014, 2015, 2016, 2017, 2018, 2019. Yearbook. - Obninsk: Ministry of Natural Resources of the Russian Federation.

7. The state (national) report on the status and use of lands of the Russian Federation 2005, 2006, 2007, 2008, 2009, 2010, 2011, 2012, 2013, 2014, 2015, 2016, 2017, 2018, 2019. - M.: Russian state register.

8. Overview of the health and environmental pollution in the Russian Federation for 2005, 2006, 2007, 2008, 2009, 2010, 2011, 2012, 2013, 2014, 2015, 2016, 2017, 2018, 2019. - Moscow: 
Gogmachadze G.D., Gogmachadze L.G. On some results of agroecological monitoring of soils and land resources of the Russian Federation in 2019

Electronic science-productive magazine

"AgroEcolnfo»

Roshydromet.

9. Report "On the state and use of agricultural lands of the Russian Federation" in 2014, 2015, 2016, 2017, 2018, 2019. - Moscow: Ministry of Agriculture of the Russian Federation.

10. On the implementation of the Federal program "Preservation and restoration of soil fertility of agricultural lands and agricultural landscapes as the national heritage of Russia for 2006-2010 and for the period up to 2013" // Information collection. Ministry of Agriculture of the Russian Federation. - Moscow, 2007.

11. Agrochemical characteristics of soils of agricultural lands of the Russian Federation (as of January 1, 2005). GNU VNII Agrochemistry named after D.N. Pryanishnikov. Russian Agricultural Academy. - Moscow, 2006.

12. Trends and dynamics of the state and pollution of the natural environment of the Russian Federation. - Moscow: Institute of Global Climate and Ecology named after Academician Yu.A. Israel, 2008-2021 [Electronic resource]. - http://dynamic.igce.ru/soil/2019/.

13. Statistics of the agro-industrial complex. Grain yield in Russia, 2001-2018. Yield of industrial crops and potatoes in Russia, 2001-2018. The yield of oilseeds in Russia, 2001-2018. Productivity of forage crops and grasses in Russia, 2001-2018. National Agrarian Agency ROSNG.RU [Electronic resource]. - https://rosng.ru/rubric/stats.

14. Liming of acidic soils in Russia: problems and current approaches. Glavagronom. 2019 [Electronic resource]. - https://glavagronom.ru/articles/Izvestkovanie-kislyh-pochv-vRossii-problemy-i-aktualnye-podhody.

15. Problems of environmental protection and ensuring environmental safety (based on the materials of parliamentary hearings) ed. Grachev V.A. - M.: Publishing house of the State Duma, 2005. $256 \mathrm{p}$.

16. Problems of degradation and restoration of agricultural land productivity in Russia. Moscow, 2008. -67 p.

17. Orlova E.E. The Effect of oil pollution on the biological activity and humic substances of soil / Diss. Cand. of agricultural Sciences. - S.-Petersburg, 1996.

18. Gilyazov M.Y. Agro-ecological characteristics disturbed by the oil of black and methods for their remediation in terms of the Kama river region of the Republic of Tatarstan / Diss. D. S.-agricultural Sciences. - Saratov, 1999.

19. Gogmachadze G.D. Agroecological monitoring of soils and land resources of the Russian Federation. - Moscow: Moscow University Press, 2010. - 587 p.

20. Gogmachadze G.D. Soil degradation: causes, consequences, ways of reduction and elimination. - Moscow: Moscow University Press, 2011. - 272 p.

21. Romanenko Yu.V. Environmental problems in the areas of oil and gas production and transportation in Western Siberia. Materials of the International Scientific conference. - Kursk, 1999. - Pp. 208-218.

22. Romanenko G.A. The state and tasks of scientific support for the sustainable development of agricultural production in arid zones of Russia // Vestnik RASKHN. - 2000. - No. 5. - Pp. 4-6. 
Gogmachadze G.D., Gogmachadze L.G. On some results of agroecological monitoring of soils and land resources of the Russian Federation in 2019

Electronic science-productive magazine "AgroEcolnfo»

23. Kuznetsov A.V., Pavlikhina A.V., Lobas N. V. Radiological monitoring of soils of agricultural lands of the Russian Federation. Agroecological problems of agricultural production in the conditions of technogenic pollution of the agroecosystem / Collection of reports of the AllRussian scientific and practical conference dedicated to the 10th anniversary of the Academy of Sciences of the Republic of Tatarstan. - Kazan: Publishing house of the Kazan State Technical University, 2001. -34 p.

24. Chernobyl 15 years later. Ed. Gerasimova N.V. - Moscow: Publishing house "ContactCulture", 2001. - 270 p.

25. Minkina T.M. Methodological aspects of soil-ecological monitoring // Fertility. -2002. - № 5 (8). - Pp. 33-35.

26. Zhuchenko A.A. Problems of food security in Russia. Collection: Health-plantbiological resources // Materials of the International scientific and practical Conference. - Kirov. - 2002. - Pp. 3-10.

27. Chupakhina G.N., Maslennikov P.V. Adaptation of plants to oil stress // Ecology. 2004. - No. 5. - Pp. 330-336.

28. Solovyov V.M. Agroecological monitoring of lands // Agrochemical Bulletin. - 2004. - No. 3. - Pp. 6-7.

29. Markina Z.N., Prudnikov P.V., Kovalev L.A. Radiological situation in the radioactively contaminated territories of the Bryansk region and ways to obtain standard-clean products. Bryansk: Agrochemradiology, 2005.

30. Barannikov V.D., Kirillov N.K. Ecological safety of agricultural products. - M.: "Kolos S", 2006. - 352 p.

31. Afanasyev R.A., Merzlaya G.E., Rusakov N.V. et al. Suitability of oil-contaminated soils for agricultural use // Fertility. - 2006. - No. 3. - Pp. 32-34.

32. Lobacheva A.A., Prokhorova N.V. Influence of oil refining production on the natural environment // Bulletin of the Samara State University. Natural science series. - 2007. - № 8 (58). - P. 138-145.

33. Seredina V.P., Andreeva T.A., Alekseeva T.P., etc. Oil-contaminated soils: properties and reclamation // Proceedings of Sibniiskhit. - 2008. - Pp. 118-123.

34. Chekmarev P.A., Lukin S.V. Monitoring of the fertility of arable soils of the Central Chernozem regions of Russia // Agrochemistry. - 2013. - No. 4. - Pp. 11-22.

35. Sychev V.G., Lunev M.I., Pavlikhina A.V. The current state and dynamics of fertility of arable soils in Russia // Fertility. - 2012. - No. 4. - Pp. 5-7.

\section{Quoting:}

Gogmachadze G.D., Gogmachadze L.G. On some results of agroecological monitoring of soils and land resources of the Russian Federation in 2019 [Electron. resource] // AgroEcoInfo: Electronic scientific and production magazine. - 2021. - No. 4. - Access mode: http://agroecoinfo.ru/STATYI/2021/4/st_410_eng.pdf.

DOI: https://doi.org/10.51419/202144101. 